\title{
O ESTADO SOCIAL E A PERÍCIA MÉDICA PREVIDENCIÁRIA COMO LIMITADORA DE DIRETOS SOCIAIS: A NECESSIDADE DE ADOÇÃO DE UM MODELO PERICIAL COMPLEXO
}

\section{THE WELFARE STATE AND THE MEDICAL EXPERTISE SOCIAL SECURITY AS LIMITING SOCIAL DIRECT: THE NEED TO ADOPT AN EXPERT COMPLEX MODEL}

\author{
Paulo Roberto Álvaro Grafulha Júnior ${ }^{1}$ \\ José Ricardo Caetano Costa ${ }^{2}$
}

\section{RESUMO}

O Estado tomou para si o encargo de proteção social dos cidadãos, por meio de políticas sociais que buscam o suprimento das condições mínimas existenciais, especialmente na falta da capacidade laboral dos trabalhadores. É nesse sentido que foram construídas as políticas de segurança, seguridade e proteção social. Por meio desta pesquisa exploratória, mediante a utilização do método dedutivo, utilizando aportes doutrinários, jurisprudenciais e legislativos, buscamos avaliar o sistema pericial utilizado no Brasil, especialmente no que respeita à aferição da incapacidade para o trabalho dos segurados.

Palavras Chaves: Estado Social. Perícia Médica. Perícia Biopsicossocial. Incapacidade. Cidadania Social.

\begin{abstract}
The state took upon itself the burden of social protection of citizens, through social policies that seek the supply of existential minimum conditions, especially in the absence of work capacity of workers. It is in this sense that were built security policy, security and social protection. Through this exploratory research, using the deductive method, using doctrinal, jurisprudential and legislative contributions, we sought to evaluate the expert system used in Brazil, especially with regard to the assessment of incapacity for work of the insured.skill complex biopsychosocial model called to ensure social citizenship to social security beneficiaries.
\end{abstract}

Keyword: Social State. Medical Expertise. Expertise Biopsychosocial. Inability. Social Citizenship.

\footnotetext{
${ }^{1}$ Bacharel em Direito e Mestrando do Programa de Pós-Graduação Stricto Sensu em Direito e Justiça Social pela Faculdade de Direito da Universidade Federal do Rio Grande -FURG, (Brasil). E-mail: grafulha jr@ hotmail.com

2 Doutor em Serviço Social pela, Pontifícia Universidade Católica do Rio Grande do Sul, PUCRS, (Brasil). Email: jrcc.pel@gmail.com
} 


\section{INTRODUÇÃO}

Pretende-se demonstrar, nesta pesquisa exploratória, a evolução do conceito de Estado e seu comprometimento com as políticas sociais de feição previdenciária, especialmente no que concerne aos direitos oriundos da incapacidade laboral.

Indagar-se-á se a perícia previdenciária, tanto no âmbito administrativo como na seara judicial, está sendo eficiente ao ponto de atender às situações de incapacidade, avaliando os segurados em todos os seus aspectos.

Dessa maneira, a fim de explorar a temática pericial, o artigo será dividido em quatro partes que tratarão o assunto de forma encadeada a fim de corroborar com os objetivos propostos.

Na primeira parte abordar-se-á a evolução do Estado até o Estado Social e de forma sucinta trará desde a idade média, onde não se poderia falar em Estado e sim em perspectivas de direitos. Abordar-se-á que com o declínio do feudalismo surge o Estado Moderno, o Estado Absolutista na figura do monarca que teve seu fim com as Revoluções Francesa e Americana no século XVIII.

Historicamente, após, há o surgimento do Estado Liberal, onde existe uma separação entre Estado e economia, o qual garante a exploração da população assalariada através do chamado capitalismo industrial, que mais tarde, dá o lugar ao Estado Social, onde há uma intervenção estatal em prol da sociedade com a criação de direitos sociais como saúde, previdência, entre outros, que garantirão melhores condições de vida.

Em um segundo momento será analisada a evolução histórica da Previdência Social que passou pelo modelo de Bismarck e Beveridge, cujas diferenciações estão na forma do custeio de cada sistema. Nessa esteira será aprofundada a situação brasileira que iniciou em 1821 com a concessão de aposentaria a professores, passou pelas Caixas de Assistência a certas categorias, a inserção no texto constitucional da Previdência Social a época, até evolução do sistema após 1988 que com a última Constituição Federal teve a criação da Seguridade Social que abarca a Saúde, a Assistência Social e a Previdência Social. 
$\mathrm{Na}$ terceira parte abordar-se-á a perícia médica previdenciária no âmbito administrativo e judicial para aferir situações de incapacidade e que não consegue alcançar o seu objetivo de prestação de um serviço que garanta os direitos dos segurados. Será examinado que o serviço não é prestado a contento, pois somente aspectos médicos referente a incapacidade são pontuados, não havendo a observância de outros nexos causais entre a saúde do segurado, suas atividades profissionais e outras de cunho social. Ademais, examinar-se-á que para o serviço pericial funcionar a contento a quantidade de profissionais deve aumentar, bem como suas capacitações através de cursos e outros estudos específicos.

$\mathrm{Na}$ última seção e a fim de garantir a dignidade dos segurados incapacitados, e tendo em vista a crítica de como as perícias médicas são realizadas, analisar-se-á a aplicação de uma perícia complexa a partir de uma avaliação médica e outra social, que conjugadas poderão aferir com maior concretude se o segurado está incapaz de exercer suas atividades habituais, qualquer atividade e até mesmo se necessitará do auxílio de terceiros para realizar os atos de sua vida diária, garantido assim um viés cidadão que traga dignidade ao segurado. Verificar-se-á que esta técnica pericial está sendo aplicada de forma incipiente e incompleta pela Justiça. Na larga maioria dos casos será perceptível que há apenas um cotejamento dos dados da perícia médica com outros dados sociais do segurado constantes no processo e não a realização de uma perícia social complementar.

\section{DO ESTADO CONTEMPORÂNEO}

O Estado Liberal surge após uma crise do Estado Absolutista, onde a burguesia apesar de encontrar seu espaço no mercado, não alcançava o poderio político, que estava nas mãos do soberano. Na virada do século XVIII com a Revolução Francesa e Americana, essa classe não se contentava mais somente com o poder econômico, queria alcançar o poder político.

Esse Estado Liberal criou uma separação entre Estado e a economia, e aquele limitarse-ia a garantir à segurança, à liberdade e à propriedade dos cidadãos com o fito de promover a paz social e oferecer condições ao livre desenvolvimento de cada um. Assim, houve uma ampliação dos poderes econômicos nas mãos dos que já detinham o capital monetário em detrimento dos direitos dos trabalhadores, deixando sempre os mais pobres, a classe operária, como explorada e cada vez mais pauperizada.

Assim, a burguesia alcançou o poder econômico para aumentar seus lucros, no chamado capitalismo (industrial), que depois vai se transformar em capitalismo monopolista. 
O papel do Estado naquela época é negativo no sentido da proteção dos indivíduos, considerando que toda a intervenção que extrapole estas tarefas é má, pois enfraqueceria a independência e as iniciativas individuais.

O liberalismo, o individualismo e o livre mercado foram fatores decisivos para a desigualdade social, estopim para as revoluções. Dentre as causas fundamentais da passagem do Estado de Direito para o Estado Social de Direito estão as revoluções sociais europeias: a soviética de 1917, a italiana de 1923 e a alemã de 1933. Como consequências revolucionárias do capitalismo citam-se a transformação da empresa individual para coletiva e a evolução da concorrência para os monopólios.

Dessa maneira, o Estado precisou intervir na economia, principalmente para garantir que problemas sociais, especialmente da classe trabalhadora, fossem melhor resolvidos diante dos efeitos trazidos pela riqueza concentrada, de um lado, o que gerava uma enorme pobreza e com ela suas mazelas, por outro lado. Ademais, quando a cidadania foi implantada, pelo menos no seu aspecto formal quando da universalização do voto, maior foi a pressão para a política liberal dos Estados intervir na economia e principalmente na esfera social, buscando garantir representatividade de uma classe que era apenas explorada para garantir maior lucratividade ao capitalismo industrial.

Em 1929 com o crack da bolsa de valores nos Estados Unidos, o Estado a fim de salvar o capitalismo implementa várias ações, de forma direta com a disponibilização de créditos, subvenções, garantias de empréstimos e de forma indireta através do financiamento público ao setor privado por meio do orçamento público e de contratos públicos (BEHRING, 2002, p. 36).

Assim, o Estado salva a economia com dinheiro público, porque enxerga que o capitalismo o alimenta, tanto que as medidas citadas têm o escopo de criar empregos no setor público e privado, assegurar o consumo de massas, aumento de salários, medidas essas inseridas diretamente na economia. E, indiretamente, a via encontrada pelo Estado são as políticas sociais, primeiramente para agradar as classes sociais mais exploradas pelo capitalismo incentivado por ele mesmo e que tem o poder do voto e secundariamente porque isso aumentaria a renda da população e o consumo.

Portanto, as políticas sociais como saúde, habitação, previdência, educação e programas sociais estão no limite entre a conquista de direitos sociais e a restruturação do capital. "Isso significa reconhecer que os direitos sociais são capitalistas e sua ampliação não 
assegura a emancipação humana, mas pode contribuir para criar as condições materiais para melhoria das condições de vida." (BOSCHETTI, 2010, p. 68).

É justamente dentro desta dialética que pretendemos analisar as políticas previdenciárias, primeiramente no mundo e depois no Brasil, para mais tarde avançarmos no sistema pericial que busca avaliar os que possuem direito (ou não) aos benefícios por incapacidade e o sistema pericial que é realizado nestes benefício.

\section{DA EVOLUÇÃO DA PREVIDÊNCIA SOCIAL}

Dentre as políticas sociais citadas, a que interessa ao presente artigo é a Previdência Social, espécie do gênero da Seguridade Social.

O marco inicial da Previdência Social é a edição da Lei dos Seguros Sociais na Alemanha de Otto Von Bismarck em 1883, que criou o seguro doença, posteriormente em 1884 o seguro acidente do trabalho, em 1889 o seguro invalidez e o de velhice. No entanto, esse marco social mundial, decorreu como já explicado acima, em decorrência de pressões sociais, cujos movimentos fortalecidos pela crise industrial urgiam direitos, os quais foram concedidos para evitar tensões sociais.

Naquela época, as leis bismarquianas tornaram obrigatória a filiação às sociedades seguradoras ou entidades de socorros mútuos por parte de todos os trabalhadores que recebessem até dois mil marcos anuais. Era um sistema de capitalização compulsório e bastante restrito, um seguro entre empregados e patrões por imposição do Estado, com contribuição de ambos, mas que só abarcava estes trabalhadores (MARTINS, 2009, p. 04).

No plano constitucional o destaque são as Constituições do México (1917) e da Alemanha (1919) que inauguram a proteção constitucional previdenciária aos trabalhadores. Já em 1942 na Inglaterra é adotado outro modelo que passou a ser chamado de Plano Beveridge, nome este dado em homenagem ao seu relator, Sir Willian Beveridge. Neste sistema, ao contrário do alemão, o sistema de proteção é mais amplo e universal, atendendo não somente os participantes que contribuem para o sistema como também aos necessitados e aos desempregados. Neste, o financiamento das políticas sociais é igualmente maior, cabendo ao Estado e a sociedade como um todo. (BEVERIDGE, 1943).

No Brasil o surgimento da previdência se deu a partir de 1821, um decreto concedeu aposentadoria aos mestres e professores após 30 anos de serviço. Em 1888 foram criadas a Caixa de Socorros para os trabalhadores das estradas de ferro de propriedade do Estado através 
da Lei 3.397 e o Decreto 9.912-A previu a aposentadoria dos empregados dos Correios após 30 anos de serviço e 60 anos de idade.

Constitucionalmente, o que se pode chamar hoje de Previdência Social após alguns aperfeiçoamentos legislativos, surgiu na Constituição de 1891 ao conceder a aposentadoria por invalidez aos funcionários públicos que se tornaram inválidos a serviço da nação, em uma época em que não se falava em pagamento de contribuição previdenciária. Em relação a Constituição anterior de 1824, o que havia era um primórdio do que seria hoje a assistência social ou saúde, porque previa apenas o que foi denominado de socorros públicos.

Cronologicamente, em 1892 a Lei 217 instituiu a aposentadoria por invalidez e a pensão por morte aos operários do Arsenal da Marinha do Rio de Janeiro. Em 1911, foi publicado o Decreto 9.284 que criou a Caixa de Aposentadoria e Pensões dos Operários da Casa da Moeda; em 1912 o Decreto 9.517 criou a Caixa de Pensões e Empréstimos para o pessoal das Capatazias da Alfândega do Rio de Janeiro; e em 1919 foi editada a Lei 3.724 que instituiu o seguro de acidente de trabalho para todas as categorias, a cargo das empresas.

Segundo Amado prevalece doutrinariamente que a Previdência Social no Brasil nasceu com o advento da Lei Eloy Chaves em 1923, através do Decreto-Lei 4.682 que criou a Caixa de Aposentadorias e Pensões para os Ferroviários, mantidas pelas empresas, haja vista que era uma categoria muito forte e numerosa naquela época (AMADO, 2012, p. 91). Essa lei é o marco do sistema previdenciário, porém não como conhece-se hoje em relação ao regime geral, porquanto as caixas eram administradas pelas próprias empresas privadas de ferrovias, ao passo que o poder público apenas regulamentava e supervisionava a atividade.

O regime da Lei Eloy Chaves posteriormente foi estendido em 1926 aos portuários e marítimos, e em 1928 para os trabalhadores dos serviços telegráficos e radiotelegráficos pelas Leis 5.109 e 5.485, respectivamente. E essa extensão benéfica culminou com o regime previdenciário, através do Decreto 20.465, aos empregados dos demais serviços públicos concedidos ou explorados pelo Poder Público.

Em 1933 através do Decreto 22.872 houve a criação do Instituto de Previdência dos Marítimos (IAPM), o que poderia ser chamada de primeira previdência pública no país, pois era gerida pela administração pública e ao contrário da Lei Eloy Chaves que criou Caixas de Aposentadoria e Pensões para determinadas empresas, ela abrangia categorias profissionais.

Posteriormente a Constituição de 1934 deu um salto no custeio do que seria comparativamente hoje a Previdência Social, pois passou a exigir contribuições do Poder 
Público, dos trabalhadores e das empresas, o que nos termos de Amado foi alterado do plano da assistência social para o seguro social, inclusive incluindo a expressão "Previdência" (AMADO, 2012, p. 93). Em 1946, com o surgimento de uma nova Constituição, o artigo 157 contempla pela primeira vez a expressão Previdência Social.

Em 1960 foi publicada a Lei 3.807, conhecida como Lei Orgânica da Previdência Social (LOPS), que unificou o plano de benefícios de todos os institutos que haviam até então. Isso engendrou, em 1967, na criação do Instituto Nacional de Previdência Social (INPS) que unificou a previdência urbana brasileira e trouxe o seguro de acidente do trabalho para o âmbito da Previdência Pública.

No ano de 1971 houve a inclusão dos trabalhadores rurais ao regime previdenciário através da Lei Complementar $n^{\circ} 11$ que instituiu o Programa de Assistência ao Trabalhador Rural (Pró-Rural), mantido pelos recursos do Fundo de Assistência ao Trabalhador (FUNRURAL). É de se frisar que nesta época perto dos $70 \%$ da população economicamente ativa (PEA) estava centrada nas zonas rurais e não participavam do regime previdenciário, assim como os trabalhadores domésticos e os do mercado informal (MELLOY, 1986).

Em 1977 foi criado o Sistema Nacional de Previdência e Assistência Social que englobava o Instituto de Administração Financeira da Previdência e Assistência Social (IAPAS) responsável pela arrecadação e fiscalização de contribuições; o Instituto Nacional de Assistência Médica da Previdência Social (INAMPS); Instituto Nacional de Previdência Social (INPS) com a atribuição de gestão dos benefícios previdenciários; Fundação Legião Brasileira de Assistência (LBA) que cuidava dos idosos e gestantes; Fundação Nacional do Bem-Estar do Menor (FUNABEM) responsável pelos menores carentes; Central de Medicamentos (CEME) que fabricava medicamentos de baixo custo; e a Empresa de Tecnologia e Informação da Previdência Social (DATAPREV) responsável pelo controle de dados.

Por fim, a Constituição Federal de 1988, por sua vez, traz um conceito de Seguridade Social antes não encontrado em nenhuma Constituição. O sistema de proteção social engloba Saúde, não contributiva e de feição universal, a Previdência, contributiva e sinônimo de seguro social e a Assistência, não contributiva e alcançada somente a quem dela necessitar.

Interessa-se, na presente investigação, analisar os direitos sociais previdenciários, de feição contributiva, portanto, não adentrando na Saúde e nos direitos assistenciais da LOAS (Lei n. 8742/03).

Com efeito, se o Estado tomou para si a gestão do sistema previdenciário, especialmente no que respeita aos benefícios por incapacidade, que são o objeto de investigação 
nesta pesquisa, cabe a ele prestar o melhor atendimento aos trabalhadores que procuram seus direitos, mormente quando não podem mais trabalhar devido a algum sinistro ou perda da capacidade laboral.

Para tanto, nestes casos, a perícia médica passa a ser o principal fator na apreciação destes direitos, pois é ela que aponta se o segurado/trabalhador está ou não com sua capacidade de trabalho prejudicada.

Esta é a questão que pretende-se examinar no tópico seguinte.

\section{DOS BENEFÍ́CIOS POR INCAPACIDADE E DA PERÍCIA MÉDICA ADMINISTRATIVA E JUDICIAL}

Desde o seu nascedouro a Previdência Social buscou assegurar a garantia dos mínimos sociais e existenciais em caso de riscos e desproteção social, especialmente quando da ocorrência de fatos e sinistros que acarretam a perda ou redução da capacidade laboral.

É justamente por isso que o auxílio-doença sempre teve assento nas primeiras leis que buscavam proteger os trabalhadores e suas famílias, tal como ocorreu na Lei dos Socorros Públicos no Brasil. Os infortúnios, tal como o adoecimento e as lesões ocorridas no trabalho, não são previsíveis, podendo ocorrer a qualquer momento e circunstância.

Neste passo é que a perícia médica administrativa sempre foi importante na verificação das patologias e suas implicações na vida dos trabalhadores, muito embora geralmente a concepção trazida pelo sistema seja muito utilitarista e pouco humanizada (COSTA, 2014).

Percebe-se que desde as Caixas de Aposentadorias e Pensões, passando pelos Institutos que lhes sucederam, como viu-se, o sistema pericial médico se fez presente para a avaliação da capacidade laboral dos trabalhadores segurados do sistema previdenciário.

E na atualidade, a perícia médica realizada no âmbito administrativo do Instituto Nacional do Seguro Social é agendada pelo segurado que sente-se incapaz de exercer seu trabalho e obter o seu sustento, tendo que o segurado levar seus exames, laudos do médico que lhe assiste a fim de que o perito possa analisá-los, realizar um breve exame se for possível e necessário naquele momento e cotejar todos os elementos como as queixas do periciando com o seu labor habitual para que possa considerá-lo capaz, incapaz de forma temporária ou definitiva, bem como uma deficiência se for o caso. A partir desse laudo a Previdência Social concederá ou não o benefício requerido. 
A questão premente sobre a temática passa pela perícia médica e sua limitação na análise da incapacidade e o seu grau a fim de nos casos de benefícios como auxílio-doença ou aposentadoria por invalidez seja possível a administração pública sopesar vários aspectos. Como informa Castro e Lazzari:

[...] a caracterização da incapacidade laboral do segurado, tanto na via administrativa como em juízo, é imprescindível a produção de prova pericial por médico que tenha domínio sobre a patologia em discussão, não sendo possível o órgão julgador tomar a decisão sem permitir ao segurado a produção de tal prova em juízo (2016, p. 785).

Nesse sentido, Savaris ressalta sobre a pericial judicial, mas que certamente é aplicável a perícia médica administrativa, que à medida que ela não cumpre seus pressupostos mínimos de idoneidade da prova técnica, ela é produzida de forma a furtar do magistrado o poder de decisão, pois respostas categóricas sem qualquer fundamentação contribuem para o decisionismo processual (CASTRO; LAZZARI, 2016, p. 787).

Outro ponto merece análise é que as perícias médicas devem pelo exposto no art. $2^{\circ}$ da Resolução ${ }^{\circ} 1.488$ do Conselho Federal de Medicina estabelecer um nexo causal entre o estado de saúde do trabalhador e suas atividades, com lastro em exame clínico e complementares, o que não é feito nas perícias administrativas do INSS, e acabam sendo infrutíferas para o que se propõe, negando benefícios de segurados especialmente o auxíliodoença e a aposentadoria por invalidez. Inegavelmente que a precariedade da resolução dos conflitos na via administrativa terminam por escoar no Poder Judiciário, em processo de judicialização dos conflitos e não na perspectiva de sua mediação. (SERAU Jr., 2015).

Os exames complementares e que devem ser considerados e conjugados com o exame clínico a fim de pormenorizar a incapacidade são entre outros a história clínica e ocupacional; estudo do local de trabalho; estudo da organização do trabalho; identificação de riscos físicos, químicos, biológicos, mecânicos, estressantes; entre outros. O que pode ser percebido é que este volume de informações impostas aos médicos peritos pelo seu próprio Conselho Profissional não é minimamente cumprido judicial, e menos ainda administrativamente.

A dificuldade, embora a resolução seja de 1998, em vigor há 18 anos, é conseguir realizar todos os procedimentos, pois certamente muitos não teriam capacidade técnica para aferir todos os quesitos o que inclusive poderia prejudicar o próprio segurado. Com efeito, sendo a resolução aplicada a todas as perícias médicas, haveriam severas alterações, pois sairia dos consultórios ou outros locais para "uma aventura no mundo real", onde teria o expert que visitar 
o local de trabalho do periciando, verificar suas condições para exercer o labor, como por exemplo, se os EPI's são fornecidos, se precisa carregar peso, subir e descer escadas, se a ergonomia do local está correta e diversos outros aspectos.

Vê-se que a correta perícia não seria aquela praticada em "linha de montagem", onde a cada cinco ou dez minutos um laudo é forjado pelos dedos através de um teclado de computador. O correto é algo que provavelmente em um dia poder-se-ia atender um ou dois periciandos Todavia, quais seriam os custos de uma política social dessa magnitude, pois seriam necessários mais servidores, mas mais relevante ainda, um treinamento constante e capacitado.

Quanto ao treinamento dos servidores, urge salientar que através do sistema DatANASPS criado pela Associação Nacional de Servidores da Previdência e da Seguridade Social é possível verificar que os atendimentos de modo geral nas agências da Previdência Social aumentou, mesmo havendo um déficit de servidores, o que faz ressaltar a produtividade, embora Souza ressaltava que há dez anos não havia treinamentos, que o número de servidores havia diminuído (SOUZA, 2012, p. 382).

Segundo aponta este autor:

Se considerarmos o indicador de concessão, entre 1991 e 2004 , comparando com o
número de servidores ativos, vemos que a produtividade cresceu quatro vezes.
Passamos de 28 concessões por servidor em 1991, com 1,3 milhões de benefícios
concedidos, para 99 em 2004, com 3,9 milhões. Já a relação entre beneficiários
(aposentados e pensionistas) por servidor praticamente dobrou entre 1991 e 2004,
passando de 267 , com 12,6 milhões de beneficiários, para 578, com 23,5 milhões. Em
1991, o INSS tinha 47,3 mil servidores ativos, e em 2004, 40,4 mil (SOUZA, 2012,
p. 383).

Assim, vê-se que há problemas estruturais no sistema de Previdência Social, que certamente não possui funcionários suficientes para prestar um serviço público a contento. Com relação especificamente aos médicos peritos, é límpido que não há treinamento para o correto atendimento do segurado, porque é conhecido que a Resolução 1.488 do Conselho Federal de Medicina não é aplicada, basta verificar que todas as perícias são realizadas em consultórios dentro das agências, sem a menor possibilidade de verificação in loco de outros fatores que concorrem para uma incapacidade laboral, situação que é repetida no âmbito judicial.

Portanto, melhores condições de trabalho deveriam ser oferecidas aos servidores do INSS, treinamento adequado e uma internalização através dos seus instrumentos normativos de métodos periciais mais abrangentes e eficazes, pois somente assim, poder-se-á atingir o que é 
prezado, o bem do segurado, haja vista que é função da Previdência Social garantir a dignidade daqueles que não conseguem pelo força do seu labor o seu sustento. Assim, demonstrar-se-á a seguir que a adoção de um outro método pericial é de substancial importância para a Previdência Social e seus beneficiários.

\section{DA PERÍCIA MÉDICA COMPLEXA E O ALCANCE DA CIDADANIA}

A perícia médica administrativa previdenciária para aferir a incapacidade dos segurados carece de aperfeiçoamento como descrito, e com essa finalidade é premente que seja estabelecida uma perícia complexa, onde o médico ou talvez outro órgão interno deveria sopesar outros fatores socioambientais que não somente os clínicos.

Assim, o que deve ser aplicado em muitas situações é a ampliação pericial, como ocorre com as perícias para a concessão de benefícios assistenciais, quando uma perícia médica e social são realizadas. Costa denomina este modelo pericial de biopsicossocial (2014, P. 33) em que também um assistente social analisa a situação social, condições familiares como quantas pessoas são sustentadas com a renda do segurado, qual a escolaridade dos membros familiares, qual a situação da moradia da família, enfim se eles estão em situação de vulnerabilidade social e se a negativa da concessão do benefício poderá agravar o estado do segurado e de seus dependentes. Busca-se assim, a percepção de Dallari sobre a justiça social: "Todos os seres humanos devem ter a possibilidade de receber os benefícios que a vida em sociedade pode proporcionar." (DALLARI, 2011. p. 12).

Além disso, a Lei 13.146/2015 traz o que seria a perícia médica complexa para aferir a deficiência, nela seria necessária uma perícia social a ser realizada por equipe multiprofissional e interdisciplinar. Essa equipe deverá analisar os impedimentos nas funções e nas estruturas do corpo; os fatores socioambientais, psicológicos e pessoais; a limitação no desempenho de atividades e a restrição de participação. Dessa forma, diversos fatores deverão ser utilizados para aferir a deficiência no caso de um segurado da Previdência Social, o que pode servir de modelo para as perícias da Previdência Social para a concessão de benefícios por incapacidade.

Como pode ser compreendido, utilizada a perícia médica e social será garantido ao segurado uma melhor análise de todos os aspectos que conjugados poderão considerá-lo incapaz de exercer suas atividades habituais, qualquer atividade e até mesmo se necessitará do auxílio 
de terceiros para realizar os atos de sua vida diária, garantindo assim um viés humanístico as perícias, a dignidade do segurado e a realização da justiça social.

Dessa forma, urge seja adotada a chamada perícia biopsicossocial, em que um assistente social fará uma perícia visitando os beneficiários, seus vizinhos, analisando documentos, entrevistando familiares, a fim de descobrir qual a situação do segurado, como é sua vida financeira, quais seus laços familiares, seu grau de instrução, entre outros elementos que um médico em uma perícia de quinze minutos de duração não consegue aferir (COSTA, 2014, p. 60).

Nesse sentido, em trabalho apresentado no $35^{\circ}$ Congresso Brasileiro de Previdência Social da LTr, ocorrido em 20 de junho de 2016, Juliana Braga, Pâmela Bolson e José Ricardo Caetano Costa apresentaram o resultado de uma pesquisa que avaliou 20 laudos periciais realizados em série, dentro de um conjunto de 100 perícias feitas em apenas quatro dias. ${ }^{3}$

Dos 20 laudos verificados, somente 8 os trabalhos periciais apontaram algum tipo de incapacidade, sendo que seis constataram incapacidade temporária, a ensejar o benefícios do auxílio-doença (B-31), enquanto somente dois pela incapacidade definitiva, apontando para a aposentadoria por invalidez (B-32).

Diante da perspectiva judicial, que presume-se seja mais abrangente, em termos de prova da incapacidade e de formas mais elásticas de convencimento do juízo, esperando-se, por consequente, uma perícia médica com um olhar mais detido acerca da falta de saúde (incapacidade) dos segurados, a margem dos $40 \%$ das perícias favoráveis aos autores dos processos judiciais parece bastante tímida.

Outro dado que chama à atenção no levantamento apresentado diz respeito a uma espécie de "alta programada"4 estipulado pelo perito judicial, nos processos em que entendeu haver algum tipo de incapacidade laboral. Em quatro laudos restou apontado o prazo exíguo de 6 meses para a suposta recuperação do autor da ação, enquanto em somente dois ficou indicado o prazo indeterminado para a recuperação.

\footnotetext{
${ }^{3}$ BRAGA, Juliana; BOLSON, Pâmela; COSTA, José Ricardo Caetano. A Pericia Médica Judicial nos Juizados Especiais Federais sob Julgamento: um recorte pequeno de um grande problema. In: $35^{\circ}$ Congresso Brasileiro de Previdência Social - Básica e Complementar. Jornal do Congresso. São Paulo : LTr., 20 jun. 2016. Caderno de Teses.

${ }^{4}$ Alta programada esta institucionalizada a partir da Medida Provisória n. 739/16, em que restou consignada a alta dos benefícios do auxílio-doença por incapacidade após os 120 dias, quando o perito não consignar qual é a data da suposta recuperação para o trabalho.
} 
Por outro lado, em nenhum deles o perito médico judicial consignou que seria caso de reabilitação e habilitação profissional. Como que em um passe de mágica, ou os autores se recuperam no prazo estipulado ou devem retornar aos seus labores, mesmo sem processo de reabilitação/habilitação profissional.

Com efeito, diante do exaurimento da perícia médica ou biomédica tradicional, diante da evidente incapacidade deste modelo na avaliação da realidade complexa e interdisciplinar que envolve a aferição da incapacidade dos segurados e autores dos processos judiciais, aos poucos percebe-se a construção de um novo sistema denominado de biopsicossocial, conforme já analisado no presente trabalho.

Enquanto a legislação previdenciária não prever uma perícia multidisciplinar, ou seja, envolvendo um médico e um assistente social, ou os juízes não requisitarem, com a provocação das partes envolvidas, como há para a concessão de um benefício assistencial popularmente conhecido como LOAS (Lei 8.742/1993), esse novo viés pericial não será aplicado pelo menos da forma como é pretendido.

Os tribunais até o momento estão aplicando de forma singela a o que talvez poderia ser chamado de perícia médica complexa (incompleta), porque não há uma análise social através de uma assistente social ou equipe multidisciplinar, como pode ser observado nestes dois ementários a seguir:

PREVIDENCIÁRIO. APOSENTADORIA POR INVALIDEZ. ACÓRDÃO EMBASADO EM OUTROS ELEMENTOS ALÉM DO LAUDO PERICIAL. POSSIBILIDADE. 1. Na análise da concessão da aposentadoria por invalidez, o magistrado não está adstrito ao laudo pericial, devendo considerar também aspectos socioeconômicos, profissionais e culturais do segurado a fim de aferir-lhe a possibilidade ou não de retorno ao trabalho. A invalidez laborativa não decorre de mero resultado de uma disfunção orgânica, mas da somatória das condições de saúde e pessoais de cada indivíduo. Precedentes. 2. O Tribunal a quo admitiu estar comprovado que a ora agravada ficou incapacitada de modo permanente e definitivo para exercer suas atividades laborativas, não obstante o laudo pericial ter concluído pela incapacidade apenas parcial. Inteligência da Súmula 83/STJ. 3. A revisão do conjunto conjunto fático-probatório dos autos que levou o Tribunal a quo a conclusão acerca da incapacidade laboral do segurado exige análise de provas e fatos, o que inviabiliza a realização de tal procedimento pelo STJ, no recurso especial, nos termos da Súmula 07/STJ. 4. Agravo regimental não provido. (STJ, AGARESP 201201337803, Segunda Turma, Relator: Castro Meira, DJE 04/10/2012)

PREVIDENCIÁRIO. CONCESSÃO DE AUXÍLIO-DOENÇA. CONVERSÃO EM APOSENTADORIA POR INVALIDEZ A PARTIR DA PERÍCIA MÉDICA. CONDIÇÕES PESSOAIS DO SEGURADO. TUTELA ANTECIPADA. 1. Comprovado pelo conjunto probatório que a parte autora apresenta incapacidade parcial e permanente, cujo início ocorreu em momento no qual havia qualidade de segurado e o período de carência se encontrava preenchido, é de ser concedido o benefício de auxílio-doença. 2. Em que pese o parecer pericial tenha indicado a 
possibilidade de reabilitação para atividade de portaria ou atividades administrativas, as condições pessoais do autor - pessoa com idade avançada, analfabeto e de histórico laboral contínuo em atividades braçais, contra-indicadas pelo perito judicial - indicam que a incapacidade apresenta características de definitividade e permanência, preenchendo o suporte fático da norma que estabelece o benefício de aposentadoria por invalidez. 3. O auxílio-doença concedido desde a data de entrada do requerimento administrativo deve ser convertido em aposentadoria por invalidez, a partir da realização da perícia médica. 4. Preenchidos os requisitos legais, a antecipação dos efeitos da tutela concedida pelo magistrado a quo deve ser mantida. (TRF4, APELREEX 50115250220114047002, Sexta Turma, Relator: Ezio Teixeira, DE 16/08/2013)

A partir da análise das duas jurisprudências pesquisadas no site http://www.cjf.jus.br/juris/unificada/Resposta com o parâmetro "aposentadoria e invalidez e condições e pessoais" é perceptível que a justiça está analisando de forma superficial as condições pessoais dos segurados para aferir principalmente a incapacidade. Os subsídios utilizados são os fatos que estão no processo como idade, profissão, grau de instrução, entre outros básicos que muitas vezes já estão entre os quesitos a serem respondidos pelo perito médico.

Não há uma perícia médica e uma perícia social, onde situações como idade, escolaridade, trabalho habitual ao longo da vida, local de moradia, aspectos familiares, entre outros de cunho pessoal e que podem influir nos casos em análise para a concessão de uma aposentadoria por invalidez ao invés de um auxílio doença e reabilitação profissional, conforme o recomendado pelo médico que não realiza o nexo causal entre incapacidade, trabalho e caráter pessoais do segurado.

Importante ainda salientar que este mesmo critério, embora mais vastamente utilizado para aposentadorias por invalidez, também pode ser utilizado para a concessão do acréscimo de 25\% nas aposentadorias do segurados da Previdência Social. Nestes casos, o segurado já está aposentado por invalidez, salvo os casos em que judicialmente é concedido para outras categorias de aposentadoria, o que restaria apenas outros aspectos a serem analisados, haja vista que a incapacidade já está superada.

Para a concessão desse acréscimo, a perícia médica pode aferir a necessidade de auxílio de um terceiro para os atos da vida diária do segurado, mas especialmente um assistente social irá in loco verificar a situação fática e poderá aferir outros aspectos mais profundos que poderão dar ensejo a concessão do chamado auxílio acompanhante. Este profissional analisará quais impedimentos ambientais do local onde reside e se por onde circula existe, por exemplo, uma pessoa cadeirante que reside no meio rural em uma casa sem adaptações, onde sabidamente 
não há ruas calçadas, não é servido por transporte público de forma adequada, o que limita sua qualidade de vida, pois dificulta a realização de atividades cotidianas sozinho, necessitando de um terceiro, requisito para a percepção do acréscimo de $25 \%$ a aposentadoria.

Administrativamente, no âmbito do Instituto Nacional do Seguro Social, não ocorre este perícia complexa, mas, felizmente, a fim de proporcionar maior profundidade na análise judicial de situações que envolvam perícias complexas, vê-se que de forma tímida alguns juízes de primeira instância estão aprofundando a temática e autorizando a perícia não somente médica como social, como ocorreu no processo $\mathrm{n}^{\mathrm{o}}$ 5000230-20.2015.4.04.7101 da Segunda Vara Federal de Rio Grande (RS).

Por outro lado, a Turma Nacional de Uniformação dos Juizados Especiais Federais, por meio da edição da Súmula n. 80, apontou pela necessidade imperativa da perícia social, além da médica tradicionalmente realizada, para a aferição da incapacidade duradoura (mais de dois anos) ou da deficiência, no caso dos benefícios assistenciais da LOAS.

Assim, percebe-se uma alteração de mentalidade, ao menos no Poder Judiciário, faltando provavelmente para a Previdência Social, como explanado no capítulo anterior, aprimorar seu atendimento no aspecto pericial com maiores aportes de recursos financeiros, pois treinamentos serão necessários e mais importante ainda, a contratação de novos servidores como médicos peritos para realizar o nexo epidemiológico, mais assistentes sociais, a fim de averiguar os aspectos citados nos parágrafos anteriores e mais analistas e técnicos do seguro social.

Neste sentido, o novo Código de Processo Civil avança no sentido do reconhecimento da perícia complexa e na correlata designação de dois ou mais peritos, quando a matéria assim o exigir (art. 475). Logo, não há dúvidas que em se tratando dos benefícios que envolvam a aferição da capacidade laboral, será necessário as duas pericias: a médica e a social. ${ }^{5}$

$\mathrm{O}$ que se pretende com a presente alteração na forma pericial dos benefícios previdenciários é uma perícia mais aprofundada, balizada em parâmetros concretos que possam levar a administração pública e o Poder Judiciário quando for o caso ao mais fidedigno convencimento.

Por fim, ao ser aplicada a perícia biopsicossocial estar-se-á aplicado o princípio da dignidade da pessoa humana, garantindo a cidadania social, pois a função do Estado nos termos de Marshall é garantir certos mínimos sociais (Apud, BIRNFELD, 2006, p. 43), o que neste

\footnotetext{
${ }^{5}$ Tal como já é feito na seara dos benefícios assistenciais e no novo benefício da aposentadoria especial dos deficientes, instituída pela Lei Complementar n. 142/13. Para tanto ver MAUSS; COSTA, 2015.
} 
caso poderá ser o direito a uma Previdência Social eficiente e competente que possa verificar em prol do segurado a sua incapacidade e lhe conceder um benefício que irá substituir sua renda a fim de poder sustentar a si e sua família. Assim, vê-se o quão primordial é um serviço pericial de qualidade, haja vista que dele depende a qualidade de vida de pessoas.

\section{CONCLUSÃO}

Buscou-se, com o presente artigo, demonstrar que a evolução do Estado trouxe valores liberais e sociais, devendo ser o objetivo do Estado garantir aos cidadãos a proteção social como forma de defesa dos mínimos sociais e existenciais, calcado no princípio da dignidade da pessoa humana. Foi justamente em decorrência disso que foram organizados os sistemas de proteção0020social, designados de seguro, seguridade, segurança social e outras designações similares que variam de país para país.

Dessa maneira, primeiramente foi abordada a evolução do Estado Contemporâneo, partindo de um Estado, onde poder-se-ia apenas analisar perspectivas de direitos, passando pelo Feudalismo, Estado Absolutista até o Liberal, no qual após o compartilhamento entre Estado e economia causou diversos prejuízos a classe trabalhadora à época. Diante disso, surge o Estado Social, onde o Estado não mais se imiscui de realizar uma intervenção em prol da sociedade, momento no qual surgem os direitos sociais, dentre eles os previdenciários que são o objeto deste artigo.

Em um segundo momento foi explorada a evolução da Previdência Social, desde as primeiras experiências com os modelos de Bismarck e Beveridge, de modo que pode-se constatar que o modelo brasileiro tem uma forte predominância do sistema de seguro alemão. Exemplo disso foram as organizações das CAPs e dos IAPs, pois protegiam somente quem estava ativamente participando do "mundo do trabalho".

Vimos que a Constituição Federal de 1988 consagra um sistema de Seguridade Social mais provedor e por consequência uma Previdência Social mais abrangente, cujas regulamentações estão menos esparsas e abrangendo mais segurados.

Na terceira seção abordou-se a perícia médica previdenciária no âmbito administrativo do Instituto Nacional do Seguro Social e judicial, explicitando a dinâmica e como esta vem sendo realizada, sem a observância de outros critérios além dos médicos, sem a realização de um nexo entre a saúde do segurado, sua atividade profissional, entre outros tantos aspectos 
abordados. Foram explicitados dados que a fim de melhorar o serviço previdenciário, e também demonstrar que há a necessidade de mais investimentos na contratação de novos servidores, bem como a capacitação constante para que possam exercer em prol do segurado suas profissões.

No último momento do artigo foi analisada a aplicação de uma perícia complexa a partir de uma perícia médica e outra social, que aferirão concretamente se o segurado está incapaz de exercer suas atividades habituais, qualquer atividade e até mesmo se necessitará do auxílio de terceiros para realizar os atos de sua vida diária, garantido assim um viés de cidadania social que traga dignidade ao segurado. Percebeu-se, através de pesquisa da jurisprudência lavrada no Superior Tribunal de Justiça e no Tribunal Regional Federal da $4^{\mathrm{a}}$ Região, que, mesmo de forma incompleta, a análise social do segurado está sendo realizada em cotejo com o laudo médico, já demonstrando a possibilidade da realização da perícia social a fim de garantir o direito a obtenção do melhor benefício ao segurado através de um estudo mais aprofundado sobre a casuística.

Portanto, conclui-se que as perícias médicas previdenciárias de forma geral não satisfazem os seus objetivos, haja vista que tanto no âmbito administrativo como judicial estão adstritas a análise apenas de aspectos médicos, duram ínfimo tempo para análise pormenorizada de exames e quadro clínico do periciando. Não é analisado o nexo epidemiológico, embora haja uma resolução do Conselho Federal de Medicina que obrigue a tanto, talvez por ela não ter sido internalizada pelo INSS em suas instruções normativas, mas certamente porque não haveria condições técnicas de realização devido a falta de treinamento e pessoal suficiente, haja vista que a perícia demoraria mais que quinze minutos.

Diante disso, o segurado incapacitado de exercer seu labor é o prejudicado, pois muitas vezes sua incapacidade não é aferida pela perícia tanto administrativa como judicial, porque outros fatores que não somente a doença não serão verificados e acabará o periciando não obtendo uma aposentadoria por invalidez ou um auxílio doença a fim de substituir a sua renda, porquanto não possui condições físicas de auferir seu sustento.

A par desse problema, que envolve os direitos de cidadania social com o objetivo de garantir a dignidade dos segurados da Previdência Social, constatou-se a premente necessidade de aplicação da perícia biopsicossocial, na qual as possibilidades de aferir com mais certeza a incapacidade e o seu grau trazem maior segurança jurídica para a concessão de benefícios previdenciários, especialmente àqueles que versam sobre a incapacidade. 


\section{REFERÊNCIAS BIBLIOGRÁFICA}

AMADO, Frederico. Direito e Processo Previdenciário. 3. ed. Salvador: Juspodivum, 2012.

BEHRING, Elaine Rosseti. Política social no capitalismo tardio. 2 ed. São Paulo: Cortez, 2002.

BEVERIDGE, William. O Plano Beveridge: relatório sobre o seguro social e serviços afins. Tradução de Almir de Andrade. Rio de Janeiro: José Olympio Editora, 1943.

BIRNFELD, Carlos André. Cidadania Ecológica. Pelotas: Delfos, 2006

BOSCHETTI, Ivanete. "Os custos da crise para a política". In Capitalismo em crise, política social e direitos. Coordenado por Ivanete Boschetti, Elaine Rosseti Behring, Silvana Mara de Morais dos Santos e outra. São Paulo: Cortez, p. 64-85, 2010.

BRAGA, Juliana; BOLSON, Pâmela; COSTA, José Ricardo Caetano. "A Perícia Médica Judicial nos Juizados Especiais Federais sob Julgamento: um recorte pequeno de um grande problema." In: $\mathbf{3 5}^{\circ}$ Congresso Brasileiro de Previdência Social - Básica e Complementar. Jornal do Congresso. São Paulo : LTr., 20 jun. 2016. Caderno de Teses.

BRASIL. Tribunal Regional Federal (4. Região). Ação Ordinária n. 5000230-20.2015.4.04.7101, 2 ${ }^{\mathrm{a}}$ Vara Federal de Rio Grande, Rio Grande, RS, 27 de julho de 2016.

COSTA, José Ricardo Caetano. Perícia Biopsicossocial: perspectivas de um novo modelo pericial. Caxias do Sul: Plenum, 2014.

CASTRO, Carlos Alberto Pereira de.; LAZZARI, João Batista. Manual de Direito Previdenciário. 19 ed. Rio de Janeiro: Forense, 2016.

DALLARI, Dalmo. Elementos de Teoria Geral do Estado. São Paulo : Saraiva, 2011.

MARTINS, Sergio Pinto. Direito da Seguridade Social. 29 ed. São Paulo: Atlas, 2009.

MALlOY, James M. Política de Previdência Social no Brasil. Rio de Janeiro: Edições Graal, 1986.

MAUSS, Adriano; COSTA, José Ricardo Caetano. Aposentadoria Especial dos Deficientes: aspectos legais, processuais e administrativos. São Paulo : LTr., 2015.

SERAU Jr., Marco Aurélio. Resolução do Conflito Previdenciário e Direitos Fundamentais. São Paulo : LTr., 2015.

SOUZA, Paulo César Régis de. A Previdência de todos. Brasília: FUNPREV, 2012. 